\title{
Executive Power Sharing in the Face of Civil War*
}

\author{
Julian Wucherpfennig ${ }^{\dagger}$ \\ Forthcoming at \\ International Studies Quarterly
}

\begin{abstract}
Scholars have debated whether executive power sharing can secure peace in multiethnic states, but concerns about endogeneity due to reverse causation render this a difficult problem for empirical analyses. In the absence of a suitable instrumental variable, I explore an actor-based approach by studying a simple formal model. This highlights the conditions under which governments are likely to share power with a domestic challenger depending on the threat of violence. I then formulate a statistical "strategic selection" model that closely mirrors the theoretical model, thereby directly incorporating endogeneity. Applied to data at the level of ethnic groups, the estimation results indicate that power sharing is indeed enacted strategically by governments in anticipation of the risk of conflict. However, shedding new light on an ongoing debate, I find that the critics have overstated the case against power sharing: rather than spurring it, power sharing robustly reduces civil conflict.
\end{abstract}

*The article has benefited greatly from insightful cooperation and comments from many individuals, in particular Lars-Erik Cederman, Simon Hug, Scott Gates, Philipp Hunziker, Nils-Christian Bormann, Nils W. Metternich, Yannick Pengl, and Lucas Leemann. All remaining errors are my own. The data underlying this article are available on the ISQ Dataverse, at https://dataverse.harvard.edu/dataverse/isq.

${ }^{\dagger}$ Professor of International Affairs and Security, Centre for International Security, Hertie School. Email: wucherpfennig@hertie-school.org. 
Current debates about the prospects of Iraq, Syria and other conflict-ridden countries bring to the fore a familiar question: is ethnic inclusiveness in the state's central executivepower sharing - a suitable means of securing peace in multiethnic states? There are many examples of successful power sharing, including South Africa, Indonesia, Northern Ireland or even Belgium and Switzerland, and power sharing has become increasingly popular in recent decades (Gurr, 2000a; Strøm et al., 2017). Yet, in other cases such arrangements have collapsed into large-scale violence, as illustrated by tragic events in Lebanon, Rwanda, Yugoslavia, Zimbabwe and elsewhere.

In view of this mixed track-record, it is little surprising that scholars disagree over the effectiveness of power sharing to peacefully govern multiethnic states. Skeptics warn that power sharing tends to deepen pre-existing divisions, undermines crosscutting cleavages, and encourages the escalation of crises between rivaling groups, making it an "impediment to peace" (Rothchild and Roeder, 2005, 29; see also Horowitz, 1985; Selway and Templeman, 2012). Many other academics and policy makers are more optimistic about the stabilizing effect of power sharing. In their view, power sharing produces peace by facilitating cooperation, reducing grievances and providing positive payoffs from peace (e.g. Lijphart, 1977; Hartzell and Hoddie, 2007; Mattes and Savun, 2009; Gurr, 2000b; Cederman, Gleditsch and Buhaug, 2013).

Does power sharing spur or reduce civil conflict? Despite the immediate policy importance of this question, we are still lacking systematic, unbiased evidence that could yield a clearer picture and guide policy-makers. In this paper I present an integrated theoretical and empirical investigation, aiming at improved inference. Specifically, previous studies have paid limited attention to problems of reverse causation, although power sharing is widely considered a deliberate policy tool for conflict management. If the causal arrow also operates in the opposite direction, then power sharing and conflict are simultaneously determined. This makes power sharing an endogenous regressor in conflict studies.

Analogous challenges are ubiquitous across the social sciences. Rodrik 2012,139$)$ warns 
that where "policies are not random but are used systematically by governments to achieve certain ends", standard regression techniques are ill-suited to evaluate their effectiveness. Indeed, a burgeoning literature suggests that institutional arrangements are endogenous to the threat of violent conflict (e.g. Acemoglu and Robinson, 2006; Svolik, 2012; Boix, 2003; Fearon, 1995). Despite its prominence in the literature, however, this theoretical claim is rarely addressed directly in empirical analyses, plausibly because the 'canonical' approach of finding a suitable instrumental variable that meets exogeneity and exclusion requirements "seems nearly impossible" (Fearon, Kasara and Laitin, 2007, 193).

Addressing this challenge head on, in this paper I explore an alternative approach that emphasizes agency and strategic interaction. I proceed in two steps. First, I introduce a simple formal model that captures the most important strategic dimension and highlights what is crucial for reverse causation: the conditions under which governments are likely to share power depending on the level of threat posed by a domestic challenger. Previous research on the origins of power sharing highlights either (1) government incentives for the co-optation of threatening challengers through power sharing arrangement (e.g. Magaloni, 2008; Roessler and Ohls, 2018), or (2) risk-diversion by means of exclusion so as to avoid perilous infighting (e.g. Roessler, 2011). Treating these as distinct theoretical possibilities, important consequences for the direction of the resulting bias emerge, since the effect of power sharing will be either overestimated or underestimated (Fearon, 2010). My model unifies these mechanisms and shows that both have their place - depending on challenger's level of threat as well as the government's ability to provide credible guarantees for power sharing.

Next, I employ a tailor-made statistical estimator that closely mirrors the strategic logic of the theoretical model. The estimator directly incorporates - and thereby endogenizesthe government's strategic decision calculus of whether or not to share power with an ethnic group, depending on its level of threat. This allows me to retrieve an improved, if not unbiased, estimate of the effect of power sharing. Applied to global, group-level data on 
powersharing and conflict, I find strong evidence that governments strategically use power sharing as a way of mitigating conflict risk. In short, power sharing is systematically endogenous to conflict. Nevertheless, I find that power sharing works much better than its reputation, and is on average a suitable means to secure peace in multiethnic states. These results hold up to several robustness checks.

\section{Power Sharing and Peace: Promises and Pitfalls}

In this section I summarize and critique the existing literature on power sharing and its effect on peace.1 I use the term "power sharing" to designate any scheme of governance that allows group representatives to engage in shared decision making through joint government within the central executive. Although a variety of dimensions have been stressed in the literature, including economic, legislative, military or territorial power sharing (e.g. Hartzell and Hoddie, 2007; Cederman et al., 2015), I explicitly focus on political power sharing within the central executive because it is widely considered the most important dimension (e.g. Strøm et al., 2017). Thus, given the (ethnic) group-level perspective adopted in this study, power sharing implies that representatives of the group participate in a formal or informal arrangement that divides executive power among leaders who claim to represent particular ethnic groups and who have real influence on political decision making. This includes ethnic coalitions in authoritarian states (e.g. Svolik, 2012), but leaves out non-ethnic arrangements, such as power sharing in Sierra Leone (Binningsbø and Dupuy, 2009).

Whether power sharing actually reduces or even breeds conflict remains the subject of debate. Many scholars claim that granting power sharing concessions eases tensions and reduces the likelihood of conflict. Much of this argument can be traced to the early writings

\footnotetext{
${ }^{1} \mathrm{~A}$ related literature examines the relationship between power sharing and democracy (for an overview, see Binningsbø, 2013).
} 
by Lijphart (1969, 1977) who advocated a set of institutional features ("consociationalism") to effectively govern pluralistic societies. This view stresses the importance of compromise and consensus (for an overview, see Binningsb $\varnothing$, 2013). A core idea is that by sharing the pie, the stakes of political contestation are lessened for all relevant parties.

Conflict researchers following this view argue that inclusive decision making will ensure that elite cooperation trumps the expected returns from (costly) conflict (e.g. Mattes and Savun, 2009, Gates et al., 2016). Several mechanisms along these lines have been proposed. Power sharing limits internal conflict by reducing ethnonationalist grievances, since meaningful representation and self-rule is central to ethnonationalist struggles (Gurr, 1993, 2000a; Cederman, Gleditsch and Buhaug, 2013). Similarly, the maltreatment of ethnic groups has been shown to trigger conflict (Petersen, 2002). A recent literature asking why power is often shared in authoritarian regimes adopts a more strategic perspective that sees offering participation in power sharing arrangements as way of co-opting potential spoilers (e.g. Gandhi and Przeworski, 2006, Gandhi, 2008; Magaloni, 2008; Svolik, 2012; Roessler and Ohls, 2018).

Other scholars advocate a more skeptical view on power sharing, pointing to an extensive list of cases in which conflict has occurred despite (or because of) power sharing (e.g. Rothchild and Roeder, 2005; Spears, 2000). In this view, by giving groups a vital and permanent role in the political process, power sharing fosters incentives to strengthen the cohesion and distinctiveness of ethnic groups (Van den Berghe, 1981; Barry, 1975; Horowitz, 1985). Accordingly, power-sharing institutions are said to provoke conflict by incentivizing ethnic outbidding and intransigence (Rabushka and Shepsle, 1972). Access to state resources may be abused by groups seeking to expand their rule (Magaloni, 2008). In the words of Rothchild and Roeder (2005, 50), under power sharing "a durable peace typically proves beyond reach." Moreover, by rewarding fighting with inclusion in power sharing, perverse incentives may have adverse spillover effects and actually encourage the use of violence as a means of getting a piece of the political pie (Spears, 2000; Tull and Mehler, 2005, see also Walter 2009). 
Existing empirical studies differ in terms of level of analysis, operationalization of the concept, as well as definition of the sample. As a result, their findings are mixed (Binningsbø, 2013). Examining the effects of various formal power sharing institutions in cross-country regressions, many studies find evidence for some form of a peace-inducing effect (e.g. Saideman et al., 2002; Reynal-Querol, 2002; Schneider and Wiesehomeier, 2008; Norris, 2008; Gates et al., 2016). By contrast, Selway and Templeman (2012) find that consociationalist institutions excacerbate political violence, rather than reduce it. Shifting the level of analysis to the group-level, Gurr (2000b) and Cederman, Gleditsch and Buhaug (2013) emphasize the grievance-reducing effect of including specific ethnic groups in power-sharing arrangements, while Roeder (2005) contends that multiple, alternating majorities with strong checks and balances are better able to prevent the escalation to ethnic violence.

A large literature examines whether the provision of various forms of power sharing in peace agreements can prevent recurrent civil conflict. Focusing on conflicts which ended in negotiated settlements exclusively, several studies find that more power-sharing provisions tend to prolong the durability of post-conflict peace (Hartzell, 1999; Hartzell, Hoddie and Rothchild, 2001; Hartzell and Hoddie, 2007; Mattes and Savun, 2009: Cammett and Malesky, 2012), especially when these are guaranteed through third parties (Walter, 1997). By contrast, comparing power-sharing agreements to other modes of conflict termination, a number of studies conclude that decisive victories tend to produce longer lasting peace, either especially for rebel victories (e.g. Toft, 2010), or government victory (e.g. Kreutz, 2010). This finding has received significant attention, since it implies that letting the parties fight it out until one side is able to completely destroy the opponent's organization (thereby preventing renewed mobilization in the future) may actually be the optimal way to secure peace in the long-run (Luttwak, 1999; Downes, 2004, though see Hartzell 2009).

While we have learned a great deal from the existing body of literature on power sharing and conflict, several shortcomings make it difficult to reconcile their contradictory findings, and to establish whether power sharing contains or spurs internal conflict. First, there has 
been a disproportional focus on cases that experienced conflict, while neglecting peaceful instances of power sharing. Indeed, many studies have asked why conflict broke out in Lebanon or Yugoslavia, while considerably less attention has focused on understanding peace in South Africa or Belgium. A large literature on post-conflict power sharing even selects their samples on the basis of prior conflict. Following Gates et al. (2016) such selective and unrepresentative coverage is likely to induce problems of selection bias. Second, many authors assume that power sharing is a country or conflict-level phenomenon. This overly aggregated perspective conceals relevant interethnic interaction and neglects that power sharing arrangements frequently include some groups while leaving out others (e.g. Nilsson, 2008). Similarly, it is often assumed that formal declarations of intent unequivocally lead to behavioral practices of power sharing. In reality this link is far from perfect, since formal power-sharing provisions are frequently not implemented (Jarstad and Nilsson, 2008, Bormann et al., 2019) $\mathrm{L}^{2}$ Thus, the third limitation in much of the existing research is an ill-suited focus on de-jure power-sharing institutions at the expense of de-facto behavior (cf. Helmke and Levitsky, 2004; Bormann et al., 2019). This focus on formal institutions is problematic because there are many instances in which power is shared in practice despite no formal accords or weak institutions (Schneckener, 2002; Spears, 2013; Roessler and Ohls, 2018). Consequently, based on the second and third limitation, formal power-sharing provisions are neither necessary, nor sufficient for actual power-sharing behavior.

In the empirical part of the paper, I address these three issues by means of suitable data that capture instances of de-facto power sharing at the level of ethnic groups (i.e. "powersharing behavior"; see Bormann et al., 2019), both before and after conflict (see Cederman, Gleditsch and Buhaug, 2013). However, one additional, yet critical limitation remains: no comprehensive empirical study takes reverse causation into account, a point developed in

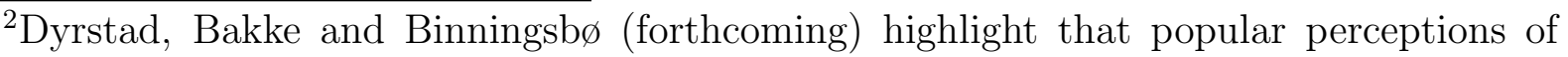
actual implementation are critical. 
more detail in the next section.

\section{Reverse Causation}

The question whether power sharing systematically limits of provokes conflict lends itself suitable to quantitative investigation, but the problem of reverse causation renders this a difficult problem for empirical analyses. Although many authors are aware of the issue (e.g. Walter, 2002; Roeder, 2005; Hartzell and Hoddie, 2007), virtually all quantitative studies effectively assume that power sharing is an exogenous regressor and unrelated to the threat of future conflict $3^{3}$ Conceptually, this stands in marked contrast to how practitioners view power sharing: as a policy tool to manage future conflict. In other words, power sharing is applied systematically in anticipation of its prospects to keep peace, and so the causal arrow also operates in the opposite direction. As is well known, neglecting reverse causation is likely to induce bias.

To the best of my knowledge, only two studies on power sharing make a concerted effort to address problems of endogeneity by pursuing an instrumental variable approach, which is arguably the standard approach to overcome such problems in observational studies (Sovey and Green, 2011). In a pioneering effort, Cammett and Malesky (2012) instrument for proportional representation on the basis of a diffusion logic in neighboring states. However, their sample is restricted to negotiated settlements after civil war, thereby dropping both peaceful instances, as well as other civil war outcomes.Wucherpfennig, Hunziker and Cederman (2016) exploit differences in colonial governance to explain inclusion in the post-colonial government, but their study is merely a cross-section of 167 ethnic groups in former French

\footnotetext{
${ }^{3}$ These studies assume that the problem of endogeneity can be "controlled away" through covariates, hinging on the strong assumption that the list of confounders is both fully observable and complete.
} 
and British colonies at the time of decolonization. In short, we are lacking a comprehensive, global assessment across space and time. Arguably this gap has been difficult to address, because persuasive instrumental variables are notoriously hard to come by in this field of research (Fearon, Kasara and Laitin, 2007, 193). In the absence of such a silver bullet, as an alternative way forward, I here leverage an actor-based approach that sees power sharing as emerging from strategic interaction between ethnic groups.

Addressing the problem of endogenous power sharing as a policy tool is equivalent to understanding the origins of such regimes. I argue that the key question amounts to understanding why and under which conditions governments are willing and able to share power with a rivaling ethnic group depending on the threat posed by the group. Viewed through this agency-lens, I build on the critique outlined above and examine jointly the causes and consequences of de facto power sharing at the group-level.

I draw on recent literature that highlights how power-sharing is a strategic tool. Two key mechanisms have been proposed. First, co-optation recognizes that to incumbent regimes, power sharing is a strategy to avoid popular uprising when exclusion is too risky and therefore not feasible Svolik, 2012; Magaloni, 2008; Przeworski and Gandhi, 2006; Gandhi, 2008; Roessler and Ohls, 2018, see also Acemoglu and Robinson 2006). In this case, the ruling group co-opts or delegates parts of the state benefits and power positions to selected groups as a way of appeasing or buying off potential challengers. Second, risk-diversion occurs within (potential) power-sharing arrangements and captures the commitment problem that is given by the fact that members to a power-sharing arrangement face incentives to monopolize power by removing their ruling partners from the government through infighting or coups (e.g. Magaloni, 2008; Roessler, 2011; Svolik, 2012, Bormann, 2019; Beiser-McGrath and Metternich, 2021). Empirical analyses suggest that some formal institutions, including legislatures, parties and even elections, can help overcome this dilemma (Boix and Svolik, 2013; Przeworski and Gandhi, 2006), while Walter (1997) highlights the role of third-partiesespecially peacekeepers - in enforcing the terms of a power sharing agreement. Recognizing 
their conceptual similarity, henceforth I simply refer to both as credible institutions.

The mechanisms of co-optation and risk-diversion have important consequences for causal inference. According to the co-optation perspective, governments exclude other groups wherever possible, while including only threatening groups. In this case, the peace inducing effect of power sharing is likely to be underestimated, because threatening groups will be overrepresented within power-sharing arrangements. By contrast, if governments exclude potential belligerents to avoid infighting, the opposite is true, and empirical estimates will be overly optimistic (Fearon, 2010; Wucherpfennig, Hunziker and Cederman, 2016). Below I present an integrated theoretical and empirical analysis that investigates the conditions under which either mechanism is likely to prevail, thereby providing a more complete picture.

\section{Theoretical Model}

I rely on a game-theoretic model to formalize the strategic logic of power sharing. For the purposes of tractability, exposition, and in order to allow for structural estimation using empirical data, the theoretical model is a first-cut and deliberately simple. I discuss several limitations, as well as possible avenues for future research in the conclusion.

The model integrates and formalizes the arguments about co-optation and risk-diversion described above, and assumes complete and perfect information. The extensive form of the game is displayed in Figure 1. The game features two actors $i$ : the government $(\mathrm{G})$, and a rivaling domestic group $(\mathrm{R})$. The two actors compete over a metaphorical pie (normalized to a value of 1) that symbolizes the incompatibility, i.e., control over the state's executive. The government moves first and either excludes $(E)$ the group from power entirely, or grants a fixed share of its power $(P S)$ to the group. Subsequently, after either government action, the group either accepts the government's action and remains peaceful $(\neg F)$, or seeks an alternative outcome by resorting to fighting $(F)$.

The payoffs are assigned as follows: If the government successfully excludes the group 


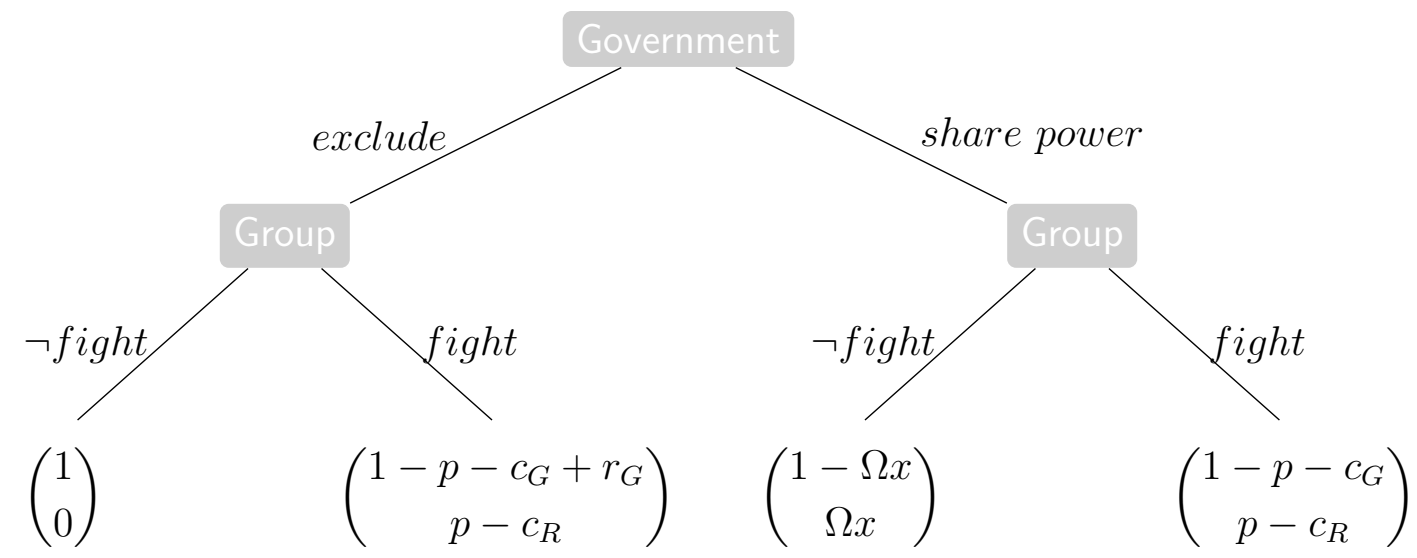

Figure 1: Extensive Form

$\{E, \neg F\}$, it keeps the full pie 1 and the group receives a payoff of 0 . Naturally, this is the preferred outcome for the government. However, the group may not accept being excluded, and can challenge the incumbent by fighting $\{E, F\}$. Following standard practice, I model this conflict as a costly lottery. Here, the group wins the full pie with probability $p \in[0,1]$, whereas G's probability of winning is $1-p$. Thus, $p$ is a measure of group strength relative to the government. Both actors have to bear a cost of fighting, denoted as $c_{i}>0, i \in\{G, R\}$. Finally, to reflect that some governments may have incentives to fight early challengers so as to deter others (Walter, 2009; Tull and Mehler, 2005; Spears, 2000), I add a reputation benefit, denoted $r_{G} \geq 0$, to the government's payoff when fighting excluded groups.

Sharing power implies that the government partially concedes control over the state's executive to the group. I denote this concession as $x \in(0,1)$, but assume that its value is fixed $]^{4}$ If the group chooses to accept this power-sharing arrangement $\{P S, \neg F\}$, a potential commitment problem holds that the concession may be revoked. Indeed, the government generally faces incentives to renege on the arrangement should a favorable opportunity arise (Magaloni, 2008, Walter, 1997; Hartzell, 2009). Thus, the value of the concession $x$ is condi-

\footnotetext{
${ }^{4}$ The equilibrium path behavior described below is analogous if $G$ chooses $x \in[0,1)$ endogenously (Online Appendix).
} 
tioned by an institutional context, denoted as $\Omega \in[0,1]$. If $\Omega=1$, the commitment problem is non-existent and the government's offer to share state power is entirely credible so that the group has nothing to fear. In theory, if $\Omega=0$, the government is entirely unable to commit to power sharing, and any arrangement is void, and effectively worthless. Higher values of $\Omega$ thus represent more credible "promises." R's payoff from peaceful power sharing is therefore $\Omega x$, whereas this value is subtracted from the pie in G's payoff, i.e. $1-\Omega x$. Thus, by considering the full range of institutions, my approach goes beyond (and complements) pioneering work by Roessler and Ohls (2018) who address ethnic power sharing in weak states characterized by strong commitment problems.

Finally, if the group is still not satisfied with this arrangement, power sharing breaks down and infighting among the power-sharing partners occurs $\{P S, F\}$, modeled as a costly lottery as before. However, because concessions have taken place, the government can no longer collect reputation benefits for being tough.

Given complete and perfect information, the model can be solved by backwards induction. Thus, I assume that each player knows the other's payoffs, and vice-versa. The solution concept is therefore the subgame perfect equilibrium. The key is that we need to understand what keeps the group from fighting. The central intuition is that power sharing can achieve this, but only under credible institutions or if neither side has a high chance of winning and conflict is sufficiently costly.

The results are also displayed graphically as a summary in Figure 2$]^{5}$ Here, the $\mathrm{x}$-axis represents a series of thresholds for the group expressed in terms of the parameter $p$, the group's relative strength. The y-axis denotes different levels of institutional credibility, i.e. the parameter $\Omega$. The different regions of the figure depict the actors' equilibrium paths according to the logic of backwards induction. In the following, I discuss five main results.

I begin by analyzing the conditions under which groups are willing to fight, along with

\footnotetext{
${ }^{5}$ The figure depicts scenarios for which $\Omega>0$, i.e. minimally credible institutions.
} 


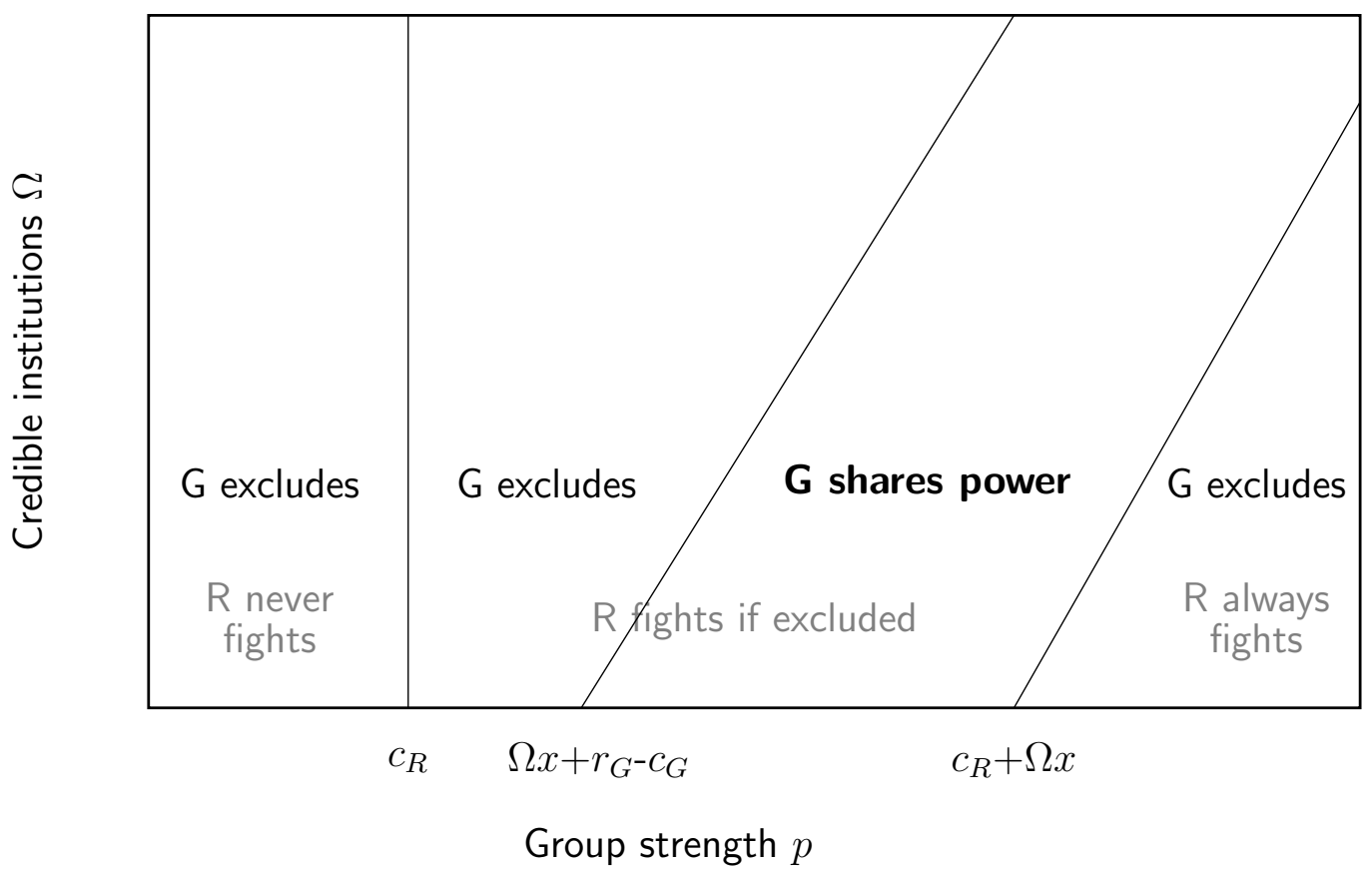

Figure 2: Visualization of Comparative Statics

the government's best response. In general, the group's decision to fight depends on whether the parameter $p$ is larger than some threshold (as given along the $\mathrm{x}$-axis in the Figure) ${ }^{6}$ Depending on this threshold, groups will either (1) never fight ('weak groups'), (2) always fight ('overwhelmingly strong groups'), or (3) fight only if excluded ('moderately strong groups').

1. Weak groups. The group's threshold for fighting depends on the probability of winning relative to the costs of fighting. Therefore $G$ never fights if $p \leq c_{R}$. Intuitively, when facing weak, non-threatening groups, the government's preferred strategy is to deny power sharing and exclude the group so as to maximize the spoils.

2. Overwhelmingly strong groups. Some overwhelmingly strong groups, however, will always fight in order to monopolize the spoils, regardless of the government's action,

\footnotetext{
${ }^{6}$ In setting (strict) equalities, I assume that ceteris paribus $R$ prefers $\neg F$ to $F$, and $G$ prefers $E$ to $P S$.
} 
and especially when the institutions are not credible. For such groups the threshold for fighting, $p$, depends on how large the costs of fighting, $c_{R}$ and expected value of powersharing, $\Omega x$ are. This equilibrium result is intuitive in the sense that strong groups will prefer the gamble of war over the gamble of power sharing, especially when the latter is associated with a high risk of losing the concession due to a looming commitment problem. Given complete and perfect information, the government anticipates this behavior by the group. Knowing that the group will always fight, it is better off by excluding the group ( always fight, the government will engage in risk-diversion and never share power (cf. Roessler, 2011).

3. Moderately strong groups. If R's strength $p$ lies in between the threshold of never fighting and the threshold of always fighting, i.e., $c_{R}+\Omega x>p>c_{R}$, then the $\mathrm{R}$ will only fight if $\mathrm{G}$ maintains exclusion. In other words, power sharing can prevent moderately strong groups from fighting. Recognizing this co-optation device, the government will consider sharing power at the cost of a smaller share of the pie. So when does power sharing make sense for the government? To analyze this question, I define a critical value of the relative strength $p^{*}$ with strict equality:

$$
p^{*}=\Omega x+r_{G}-c_{G} .
$$

At this critical value, the government is indifferent between exclusion and granting power sharing. If $p \leq p^{*}$, the government will prefer exclusion even though the group will resort to fighting. By contrast, to prevent conflict the government will have to offer the concession of power sharing. The government will do so if $p>p^{*}$. In other words, power sharing is attractive to the government when faced by moderately threatening challengers. More so, the model presented here implies that power sharing will not even be offered unless the government is faced by a militarily strong challenger. In short, 
power sharing is a strategy of co-optation to keep a domestic group from fighting where they otherwise would.

Next, I examine more closely the conditions for and consequences of power sharing.

4. Contrary to much of the literature - but in line with Boix and Svolik (2013) and Roessler and Ohls (2018) - Figure 2 shows that power sharing can be sustained if institutions are minimally credible, provided that neither the government nor the group is overwhelmingly strong. In other words, under weak institutions power sharing can exist in equilibrium if it is self-enforcing through a mutual threat, that is when both parties are roughly equal in their thresholds for fighting.

However, fostering credible institutions can help bring about power sharing - and thereby peace - under specific conditions, namely when the challenging group is overwhelmingly strong, and the government is a minority. In Figure 2 this means moving from the lower right corner to the upper right corner.

5. Finally, in the model groups never fight when included in a power-sharing arrangement, but only if they are excluded. In short, according to the theoretical model, power sharing is associated with peace.

In sum, the theoretical model details the core strategic logic of power sharing in the face of civil war. It offers a unified account that comprises both the logics of co-optation and riskdiversion in the same model, and thus speaks to the question when and why governments are willing and able to share power with a domestic challenger depending on the level of threat. This question, I had argued, is key to addressing head on the empirical challenge of reverse causation. Thus, I now turn to the second step of my empirical strategy and develop a statistical estimator that mirrors the theoretical model, thereby directly incorporating reverse causation. This allows me to test specific predictions, as well as the formal model in general. 


\section{Empirical Estimation of the Game}

In this section, I formulate a statistical model on the basis of the formal model. I then discuss how the specifics of this estimator allow me to address problems of endogeneity, and thereby improve empirical estimates. At a basic level, the theoretical model suggests how the decision to enact a power-sharing arrangement and the decision to fight are strategically interdependent. In this case, conventional estimators, such as logit or probit, can lead to serious bias (Signorino and Yilmaz, 2003). To overcome such problems, I employ a statistical estimator that models the government's decision to grant power sharing or exclude, as well as the group's decision to accept this choice or resort to fighting as endogenous choices. By explicitly modeling how the government strategically anticipates the group's response, I am able to deal with endogeneity problems that arise from strategic interaction (see e.g. Signorino, 1999; Carter, 2010).

The theoretical model depicted in Figure 1 assumes that neither the government, nor the group make any errors in their decision making - which I relax in order to write down a statistical model based on the underlying theoretical model. Specifically, I make the plausible assumption that both actors are boundedly rational (Simon, 1955) by erring stochastically in making the optimal choice. Assuming a particular probability distribution for the actor's error terms (see below), it is possible to derive a variant of the quantal response equilibrium (QRE) solution concept (McKelvey and Palfrey, 1998). The QRE includes the subgame perfect equilibrium solution concept as the special case in which neither actor makes errors (Signorino, 1999). The statistical model is therefore structurally consistent with the theoretical model, but also more general because it allows for the possibility that errors in decision-making occur at times. This allows me to estimate the players' utilities directly from empirical data.

I introduce the logic of the statistical model by deriving for each player latent variables that reflect the differences in utilities from the relevant choice alternatives (with error). The notation is depicted in Figure 3. The players choose their actions based on the expected 


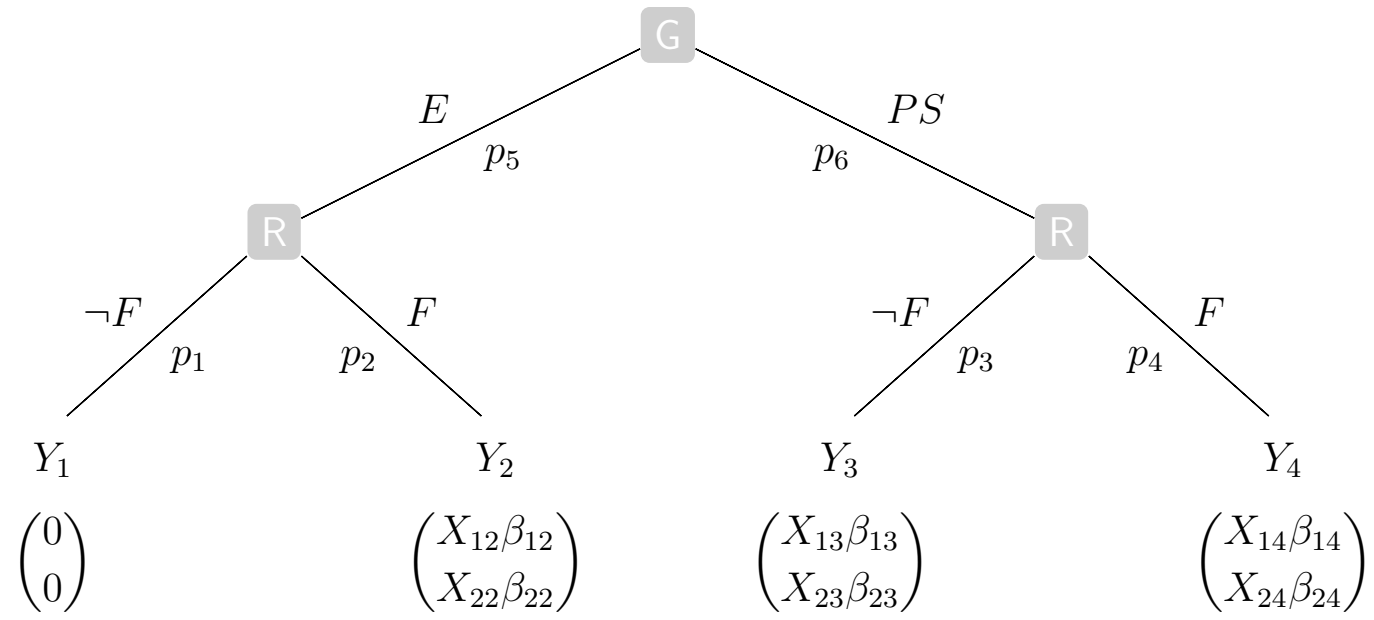

Figure 3: Empirical Model

difference in utilities (with error). For $G$ this means deciding between excluding the group, or sharing power

$$
\Delta\left(U_{G}\right)=y_{G}^{*}=U_{G}(P S)-U_{G}(E)+\epsilon_{G}
$$

while for $R$ this means deciding between staying peaceful and resorting to arms

$$
\begin{gathered}
\Delta\left(U_{R, E}\right)=y_{R, E}^{*}=U_{R, E}(F)-U_{R, E}(\neg F)+\epsilon_{R, E} \\
\Delta\left(U_{R, P S}\right)=y_{R, P S}^{*}=U_{R, P S}(F)-U_{R, P S}(\neg F)+\epsilon_{R, P S}
\end{gathered}
$$

depending on whether $G$ previously played $E$ or $P S$. The conventional strategic estimator would then assume that the four possible outcomes, $Y_{1}, \ldots, Y_{4}$ arise as the joint probabilities of the players' actions (e.g. Signorino, 1999; Carter, 2010). However, Leemann (2014) explains that this implies the problematic assumption that the error terms between the players are uncorrelated, i.e. $\operatorname{corr}\left(\epsilon_{G}, \epsilon_{R, E}\right)=\operatorname{corr}\left(\epsilon_{G}, \epsilon_{R, P S}\right)=0$, which is likely to induce selection bias (cf. Signorino, 2002). Intuitively, such selection problems may arise if those groups included in power sharing arrangements are systematically different from excluded groups. In the context of strategic estimators, selection problems may be due to unobserved common shocks and/or unmodeled variables which contribute to both players' utilities (Leemann, 2014. 
378). Howevever, sample selection may even lead to biased estimates even if selection occurs entirely on observables, namely when the actors utilities overlap on certain key variables as is the model analyzed above (Leemann, 2014).7

Following Leemann (2014), the strategic selection estimator used here avoids the problem of sample selection by allowing for the government's and the groups' error terms to be correlated via a bivariate distribution. As detailed in the next subsection, this is critical to overcome endogeneity problems when estimating the effectiveness of the government's choice on the probability of conflict. The estimator can be considered a hybrid between the conventional strategic estimator (Signorino, 1999), and a Heckman sample selection probit. Specifically, the four possible outcomes given by the joint probabilities of the players' actions are modeled as:

$$
\begin{gathered}
\{E, \neg F\}: P\left(Y_{1}\right)=\Phi_{2}\left(-\Delta U_{G} ;-\Delta U_{R, E} ; \quad \rho_{1}\right) \\
\{E, F\}: P\left(Y_{2}\right)=\Phi_{2}\left(-\Delta U_{G} ; \Delta U_{R, E} ;-\rho_{1}\right) \\
\{P S, \neg F\}: P\left(Y_{3}\right)=\Phi_{2}\left(\Delta U_{G} ;-\Delta U_{R, P S} ;-\rho_{2}\right) \\
\{P S, F\}: P\left(Y_{4}\right)=\Phi_{2}\left(\Delta U_{G} ; \Delta U_{R, P S} ; \rho_{2}\right)
\end{gathered}
$$

where $\Phi_{2}$ is the bivariate standard normal cumulative density function with correlation $\rho$. Thus, I assume the players' errors to follow a normal distribution. Put differently, the conventional strategic probit estimator is nested in my approach as the special case where

\footnotetext{
${ }^{7}$ In that case the constant may be biased, and consequently, predictions will be biased as well Achen, 1986, 78-79). This matters for the way in which I calculate the effect of power sharing on conflict (see below).
} 
$\rho_{1}=\rho_{2}=0.8$

Drawing on Equations 2 and 3, the next step is to reformulate the estimator given in Equation 4 in terms of utility over outcomes:

$$
\begin{aligned}
& P\left(Y_{1}\right)=\Phi_{2}\left(\quad p_{1} U_{G}\left(Y_{1}\right)+p_{2} U_{G}\left(Y_{2}\right)-p_{3} U_{G}\left(Y_{3}\right)-p_{4} U_{G}\left(Y_{4}\right) ; \quad U_{R}\left(Y_{1}\right)-U_{R}\left(Y_{2}\right) ; \quad \rho_{1}\right) \\
& P\left(Y_{2}\right)=\Phi_{2}\left(\quad p_{1} U_{G}\left(Y_{1}\right)+p_{2} U_{G}\left(Y_{2}\right)-p_{3} U_{G}\left(Y_{3}\right)-p_{4} U_{G}\left(Y_{4}\right) ;-U_{R}\left(Y_{1}\right)+U_{R}\left(Y_{2}\right) ;-\rho_{1}\right) \\
& P\left(Y_{3}\right)=\Phi_{2}\left(-p_{1} U_{G}\left(Y_{1}\right)-p_{2} U_{G}\left(Y_{2}\right)+p_{3} U_{G}\left(Y_{3}\right)+p_{4} U_{G}\left(Y_{4}\right) ; \quad U_{R}\left(Y_{3}\right)-U_{R}\left(Y_{4}\right) ;-\rho_{2}\right) \\
& P\left(Y_{4}\right)=\Phi_{2}\left(-p_{1} U_{G}\left(Y_{1}\right)-p_{2} U_{G}\left(Y_{2}\right)+p_{3} U_{G}\left(Y_{3}\right)+p_{4} U_{G}\left(Y_{4}\right) ;-U_{R}\left(Y_{3}\right)+U_{R}\left(Y_{4}\right) ; \quad \rho_{2}\right)
\end{aligned}
$$

where

$$
\begin{aligned}
& p_{2}=1-p_{1}: p_{2}=\Phi\left(U_{R}\left(Y_{2}\right)-U_{R}\left(Y_{1}\right)\right) \\
& p_{4}=1-p_{3}: p_{4}=\Phi\left(U_{R}\left(Y_{4}\right)-U_{R}\left(Y_{3}\right)\right)
\end{aligned}
$$

Written this way, the log-likelihood function is simply the joint probability of the outcomes:

$$
\ell \ell=\sum_{i=1}^{N} \log P\left(Y_{1}\right)^{Y_{1}}+\sum_{i=1}^{N} \log P\left(Y_{2}\right)^{Y_{2}}+\sum_{i=1}^{N} \log P\left(Y_{3}\right)^{Y_{3}}+\sum_{i=1}^{N} \log P\left(Y_{4}\right)^{Y_{4}}
$$

This function can then be optimized using standard maximum likelihood estimation by parameterizing the players' utilities over outcomes using empirical data. For example, $X_{12} \beta_{12}$ is the vector of covariates with corresponding parameters capturing the utility for player 1 $(G)$ for outcome $Y=2$ (see Figure 3 ).

${ }^{8}$ Signorino $(1999)$ and others typically use a denominator of $\sqrt{2}$ to reflect variances of $\sigma=1$, but this is for identification only and makes no difference other than scaling the estimates (see Leemann, 2014, 377-378). 


\section{Sources of Bias: Strategic Expectations and Sample Selection}

Before detailing my choice of variables to parameterize the players' utilities, I discuss how the estimator given in Equation 5 directly incorporates strategic expectations, as well as sample selection, thereby overcoming two key sources of bias. The government's choice is based on a comparison between the utilities for the respective outcomes that are associated with choosing $E$, i.e. $U_{G}\left(Y_{1}\right)$ and $U_{G}\left(Y_{2}\right)$, and choosing $P S$, i.e. $U_{G}\left(Y_{3}\right)$ and $U_{G}\left(Y_{4}\right)$. Having made either choice, it is up to the group to decide which outcome materializes. Since this is not a fully random choice, the government weighs the utility of each outcome by the group's (anticipated) choice probabilities (denoted $p_{1}, \ldots, p_{4}$ ). In other words, the government makes expected utility calculations that incorporate the probabilities that the group will remain peaceful or decide to fight.

By contrast, given that the rivaling group moves last, its decision calculus does not factor in any anticipated government reaction. Critically, those groups that choose between staying peaceful and fighting under exclusion might be systematically different from those that are granted power sharing, and some of these differences might not be fully observable to the analyst. This could lead to selection effects that bias the estimates for the group's utilities. Referring to the conventional strategic estimator (i.e. Equation 5 with $\rho_{1}=\rho_{2}=0$ ) Leemann (2014, 374; see also Signorino, 2003) explains that

Compared to nonstrategic estimators, strategic models are even more prone to selection effects. First, external shocks or omitted variables can lead to correlated errors. Second, because the systematic parts of actors' utilities usually overlap on certain key variables, the two sets of explanatory variables are correlated. As a result, both the systematic and the stochastic components can be correlated. However, given that the estimates for the first mover are computed based on the potentially biased predicted probabilities of the second actor, we also generate biased estimates for the first actor. 
Thus, while strategic action affects the government's estimates, selection bias also affects the group's estimates. Indeed, both potential causes for selection bias are plausible given the current application. 9 For example, in the theoretical model, the parameter $p$ (denoting the relative balance of power between the group and the government) is relevant to both players and therefore operationalized empirically through the same covariate (see below). This creates overlap on a key variable. Indeed, the theoretical model suggests that less threatening groups are less likely to be included in power sharing. As a result, I expect $\rho_{1}$ to be negative.

Similarly, despite careful attempts to properly specify the model, it is plausible that omitted variables or external shocks render some groups more or less threatening, which affects their propensity for being included in a power sharing arrangement. For example, my operationalization $p$ (detailed below) is based on the relative demographic balance of the group vis-à-vis the government. Of course this is but one determinant of a group's level of threat, and many others are conceivable, including the availability of arms (which is hard to measure at the group-level). The estimator introduced above explicitly addresses such problems by allowing for correlated errors, thereby generating consistent, unbiased and efficient estimates in the presence of both selection and strategic action ${ }^{10}$ This will be of particular importance when I use the estimator to obtain an estimate of the effectiveness

\footnotetext{
${ }^{9}$ For analytical tractability the estimator assumes that the players are not aware of the correlation between error terms, unlike the estimator proposed by Signorino 2002). Leemann (2014) shows that this assumption makes little difference even if the DGP is based on a 'known' correlation.

${ }^{10}$ Strictly speaking the estimator does not require an exclusion restriction. Although the theoretical model predicates that some covariates are only relevant for $G$ (which could be considered quasi instruments), identification is secured through non-linearities arising from strategic interaction, and/or bivariate normality in errors, similar to a bivariate probit model (Wilde, 2000).
} 
of power sharing as means of preventing civil conflict by comparing the group's predicted probabilities to fight depending on the government's choice.

\section{Data}

Having introduced the statistical estimator, I now detail the data and explain how I operationalize governments' and rivaling groups' decisions, and how I paramaterize their utilities. To test the theory, I require disaggregated data that capture the interaction between ethnic groups and governments, including information on power sharing and fighting in civil conflicts. My primary data source is therefore the Ethnic Power Relations dataset (EPR, version 2018; see Vogt et al., 2015).11 EPR provides a global dataset of all 853 politically relevant ethnic groups worldwide, 1946-2017. Political relevance denotes groups that are active in national politics and/or directly discriminated against by the government.

The EPR dataset is particularly suitable for my purposes because it measured at the group-level and offers information on groups' de facto inclusion in (or exclusion from) executive power. Depending on the country, executive power is either the presidency, the cabinet, or senior posts in the administration, including the army. Moreover, it is noteworthy that EPR is time-variant in its coding, i.e. it captures major shifts in the power constellation across time. EPR distinguishes between three major types of access to executive power based on whether the group (1) rules alone, (2) shares power, or (3) is excluded from executive power. The second set of power configurations captures de facto executive power-sharing arrangements, regardless of whether such arrangements arose due to formal rules or not (i.e. power-sharing behavior, cf. Bormann et al., 2019). Thus, groups that share power enjoy meaningful representation within the country's executive, while excluded groups have no regular representation within the executive. For example, for Iraq 2012-2017, EPR iden-

${ }^{11}$ The data were obtained via http:/growup.ethz.ch/rfe/. More information on EPR is provided in the Online Appendix. 
tifies Shi'a Arabs and Kurds as power sharing partners, while Sunni Arabs, Turkmen and Assyrians are excluded.

I use these group-level data to construct yearly group-government dyads using as the basis all groups that are either included in a power-sharing arrangement or excluded. I consider 'the government' to be all groups which are not excluded, minus the group itself if the groups is part of a power sharing arrangement. Groups which rule alone cannot fight the state by definition and are therefore dropped from the analysis as no meaningful dyad can be constructed in such cases (see Cederman, Wimmer and Min, 2010). ${ }^{12}$ Set up this way, I model the game as being played yearly (cf. Carter, 2010). While my approach focuses squarely on strategic interdependence other types of dependence may also be present in the including interdependence between multiple dyads in the same country, as well as temporal autocorrelation. Recognizing these limitations, and far from being perfect, I attempt to account for these through relevant covariates. I return to these issues in the conclusion.

Decision variables. As a direct reflection of the theory, the distinction between exclusion and power sharing is used as the government's decision variable. To capture the group's decision to fight (or remain peaceful), I rely on a group-level coding of the outbreak of civil conflict onset on the basis of the Uppsala Conflict Data Programm's Armed Conflict Dataset, which requires at least 25 battle-related deaths in an intrastate conflict between a government and a non-governmental party in one calendar year (Gleditsch et al., 2002). Specifically, the ACD2EPR dataset provides a mapping for each conflict onset onto corresponding EPR group(s), provided that the rebel organization recruited from and claimed to operate on behalf of the group (Wucherpfennig et al., 2012) ${ }^{13}$ Overall, there are 221 group conflict onsets in the data, and 10,644 group years of power sharing (out of a total of 29,734

\footnotetext{
${ }^{12}$ However, these groups represent the government for groups from the respective countries.

${ }^{13}$ This includes violent coups that exceed the battle-related deaths threshold, but excludes non-violent ones.
} 
observations). Jointly, the variables for exclusion/power sharing and conflict onset yield the four outcomes of the theoretical/empirical model.

Empirical Specification of Utilities. In specifying government and group utilities, my general strategy is to strictly follow the theoretical model given in Figure 1 and operationalize each pay-off component through one or more relevant covariates. Thus, I attempt to approximate the logic of the theoretical model as closely as possible. Since the strategic selection estimator adds considerable complexity in terms of computational demands and interpretation, a parsimonious specification is essential.

To allow for identification, I need to set the utility of at least one outcome per player to zero. This provides a baseline for each player, and all other estimates will have to be interpreted relative to this base category. Given the theoretical model, the straightforward choice for the group is set $U_{R}\left(Y_{1}\right)=0$, since this outcome is also zero in the theoretical model. Because the government only compares her own utilities, I can simply normalize by subtracting a value of 1 from each of her payoffs, thereby also setting $U_{R}\left(Y_{1}\right)=0$ (see Figure 11. As a result, I specify three sets of covariates per player ${ }^{14}$ Rather than discussing the parameterization of each utility separately, I discuss how each pay-off component is operationalized, with the understanding that the full parameterization of each utility then follows directly from Figure 1.

Relative Group Strength $p$. To capture this parameter, I rely on the group's demographic balance relative to the government. For an excluded group $i$, this is computed as $p_{E, i}=$ $s_{i} /\left(s_{i}+\sum_{j} s_{j}\right)$, where $s$ denotes the group's relative share of the population as provided by EPR, and $j$ denotes all (other) groups that currently hold executive power. For groups included in power sharing this is $p_{P S, i}=s_{i} / \sum_{j \neq i} s_{j}$ (see Buhaug, Cederman and Rød, 2008), i.e. the group is pitched against all remaining groups in the government. Constructed this

\footnotetext{
${ }^{14}$ Strictly speaking, $X_{23} \beta_{23}$ is subsumed in $X_{24} \beta_{24}$ in my empirical estimation, but this merely changes sign, as can be seen in Equation 3 .
} 
way, $p \in(0,1)$ adequately reflects the theoretical model. Relying on demographic shares as a measure of strength is widely accepted (Bhavnani and Miodownik, 2009, Cederman, Gleditsch and Buhaug, 2013) and has several advantages, including that it is available at the level of ethnic groups.

Cost of fighting $c_{i}$. Following standard practice, I use GDP per capita (Gleditsch, 2002) to operationalize the (opportunity) cost of fighting for both actors (e.g. Fearon and Laitin, 2003). In addition, I include the logged number of years since the last conflict (peaceyears). A dummy variable for previous conflict allows me to distinguish between pre- and postconflict situations. It can be expected that opportunity costs in post-conflict situations are lower, for example due to the availability of trained fighters, small arms, or feelings of revenge. Following Cederman, Gleditsch and Buhaug (2013), I also include a dummy for ongoing conflict during the previous year, reflecting lower mobilization costs. Together these variables also address issues of event and duration dependence (Carter and Signorino, 2010)

Reputation benefits $r$. Governments should be more inclined to accept fighting excluded groups when doing so can deter future challengers. In other words, they will benefit more from risking exclusion where they are faced with a large number of potential challengers, especially early on (see Walter, 2009; Tull and Mehler, 2005). In order to operationalize this argument, I rely on the logged number of excluded groups in the country (minus the group itself), interacted multiplicatively with the dummy for previous conflict.

I now turn to the part of the model that is most difficult to operationalize, the size of power sharing concessions and how credible these concessions are, i.e. the commitment problem.

Credible institutions $\Omega$. The theoretical model highlights how institutions lend credibility to the promise of power sharing concessions, since incentives to renege will prevail. While operationalizing this commitment problem is challenging, I here exploit the insight that particular institutions may serve as a constraint on the government's ability to renege on the promise of power sharing. In particular, it can be expected that constraints on the central 
executive (i.e. the government), for example through legislatures or an independent judiciary, will make power sharing more credible to the challenger. Following this line of reasoning, I use the XCONST dimension ("executive constraints") of the PolityIV data (Marshall, Gurr and Jaggers, 2017) to capture the degree to which institutions are credible ${ }^{15}$ XCONST is a 7-point scale that captures "the extent of institutionalized constraints on the decision making powers of chief executives" that is exercised by "accountability groups", such as legislatures in Western democracies; "the ruling party in a one-party state; councils of nobles or powerful advisors in monarchies; the military in coup-prone polities; and in many states a strong, independent judiciary" (Marshall, Gurr and Jaggers, 2017, 24). Higher values denote larger constraints on the executive. Alternative operationalizations of $\Omega$ are considered in the robustness analyses.

Share of power $x$. Finally, I require an indicator of the size of the concession that the government transfers to the group, i.e. the share of state power the group holds under power sharing. Empirically, it is difficult, if not impossible, to measure this aspect independently of the relative strength parameter $p$, especially counterfactually for groups not currently included in a power sharing arrangement.16 ${ }^{16}$ I therefore make the additional assumption that in the empirical model, $x$ is also captured by the group's demographic share relative to the government.17 This is empirically warranted, since Francois, Rainer and Trebbi 2015, 465) convincingly show that within African power sharing arrangements "political power is

\footnotetext{
${ }^{15}$ I follow Gleditsch and Ruggeri (2010) and replace periods of interregnum with the minimum value so as to maximize the number of observations, and especially conflict onsets. Substantively, periods of interregnum are associated with great uncertainty, effectively preventing credible commitment.

${ }^{16}$ The counterfactual measure is necessary to be able to calculate the effect of power sharing on conflict.

${ }^{17}$ Conceptually, this implies a positive affine transformation (rather than that $x=p$ ) and does not restrict the set of subgame perfect equilibria described above.
} 
allocated proportionally to population shares across ethnic groups."

\section{Main Results}

I estimate the model using standard maximum likelihood techniques with an analytical gradient and strict convergence criteria to ensure optimization. Following Carter (2010), I present more conservative (non-parametric) bootstrapped standard errors derived across 500 iterations 18 The estimation results are given in Table 1. Each column denotes the estimates for the utilities of a particular outcome for a given actor, and shows coefficients along with standard errors in parentheses below. In general, for the statistical model to be consistent with the formal model, the (non-interacted) coefficients associated with each payoff component should be consistent with Figure 1. Eyeballing reveals that on the whole, the theoretical model is largely supported, since most estimated coefficients show the expected $\operatorname{sign} 19$

Before turning to the two core questions about (1) the strategic origins, and (2) the effects of power sharing on conflict, I briefly comment on the players' utilities. According to the strategic selection model, governments are more inclined to fight a rivaling excluded group under low GDP per capita, shortly after previous conflicts, and when there is conflict ongoing that involves another group. Moreover, in line with reputation arguments I find that governments benefit from fighting in the presence of multiple challengers, especially early on ${ }^{20}$ When the rivaling group is included, however, the government's utility for fighting in-

\footnotetext{
${ }^{18}$ Analytical standard errors derived via the inverse Hessian are generally smaller and are available upon request.

${ }^{19}$ Note that coefficients for $U_{G}(E, F)$ and $U_{G}(P S, F)$ appear large, but this is because these utilities are scaled by very low baseline probabilities of fighting ( $p 2$ and $p 4$; see eq. 5) due to conflict being a rare event.

${ }^{20}$ For post-conflict situations, the relevant effect is the sum of the coefficient for the number of excluded groups and the interactive term, i.e. $243-204=39$, which is substantially
} 


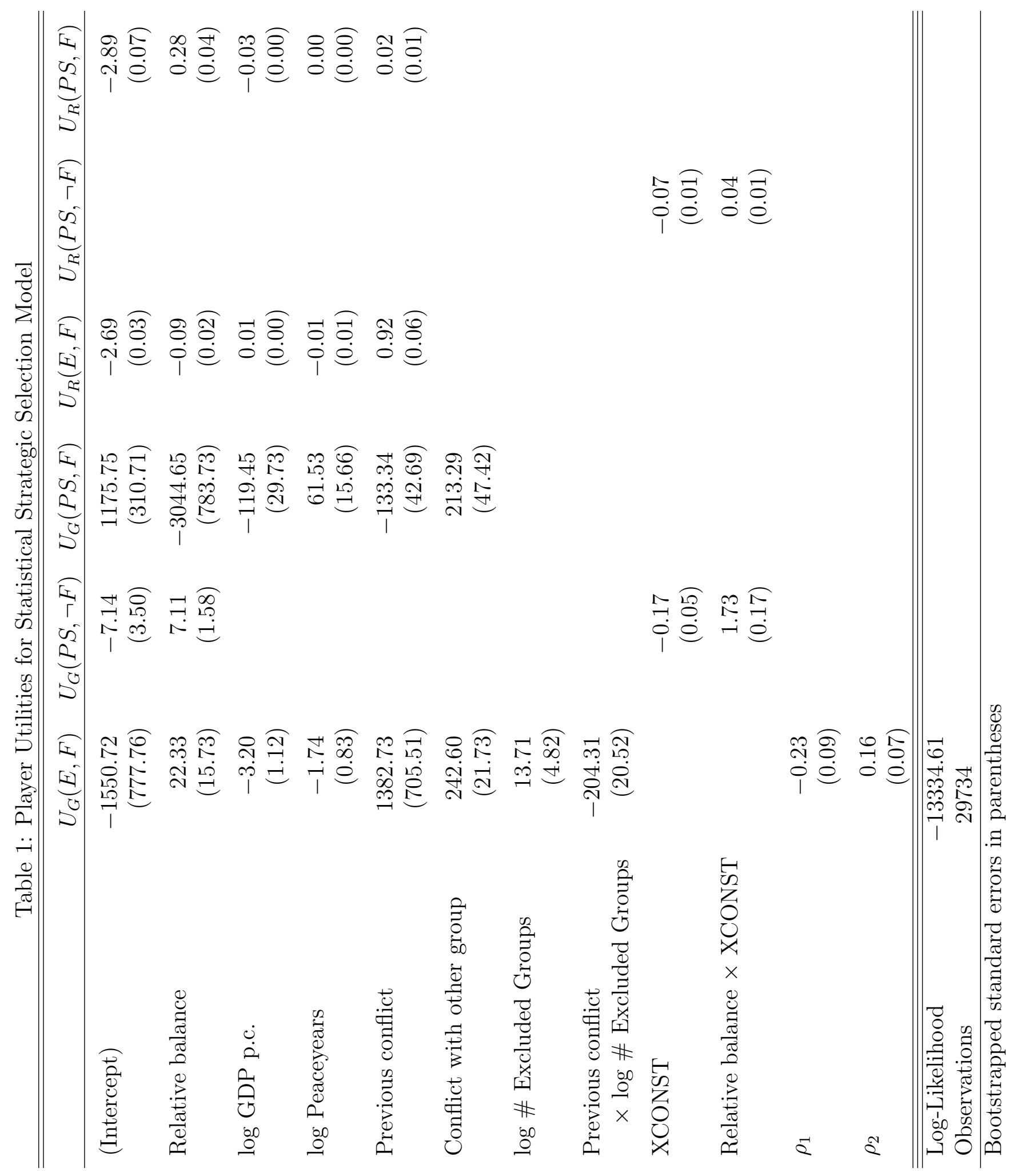


creases when GDP is low, and the longer peace has endured. Here, too, ongoing conflict with another group elsewhere raises the government's utility for fighting. Turning to the group's utilities, for a rivaling group that is excluded, high GDP increases the utility of conflict, as does enduring peace and no prior conflict. When the group is part of a power sharing arrangement, fighting can be beneficial when GDP is low, when it has fought previously, and after long lapses of peace.

\section{Origins of power sharing}

Building on these estimated utilities, I now shift the focus to two core questions. First, under what conditions are governments likely to share power with a rivaling group? Second, accounting for this endogenous choice, does power sharing limit (or even spur) the risk of armed civil. With regard to the former, the key insight of the theoretical model has been that the threat of conflict informs the government's choice whether to share power with the group, and that this is conditioned by how credible the promise of power sharing is for the group. Along these lines, in Figure 4 I use the strategic selection model to generate predicted probabilites for the government's choice as a function of how strong the group is relative to the government (the parameter $p$ operationalized as the relative demographic balance), as well as the credibility of the institutions $(\Omega)$ operationalized as executive constraints). This goes beyond existing work, which has focused on weak institutional settings, especially Africa (Roessler and Ohls, 2018; Wucherpfennig, Hunziker and Cederman, 2016), and provides a comprehensive account that covers a wide range of (global) settings. Strikingly, the figure yields close resemblance to the equilibrium results of the theoretical model (see Figure 2). In

particular, the statistical model also predicts that weak groups generally have a low probability of being part of power-sharing arrangements. Theoretically, this is because these groups do not pose a credible threat to the government, and thus there is no need to accommodate

smaller. 


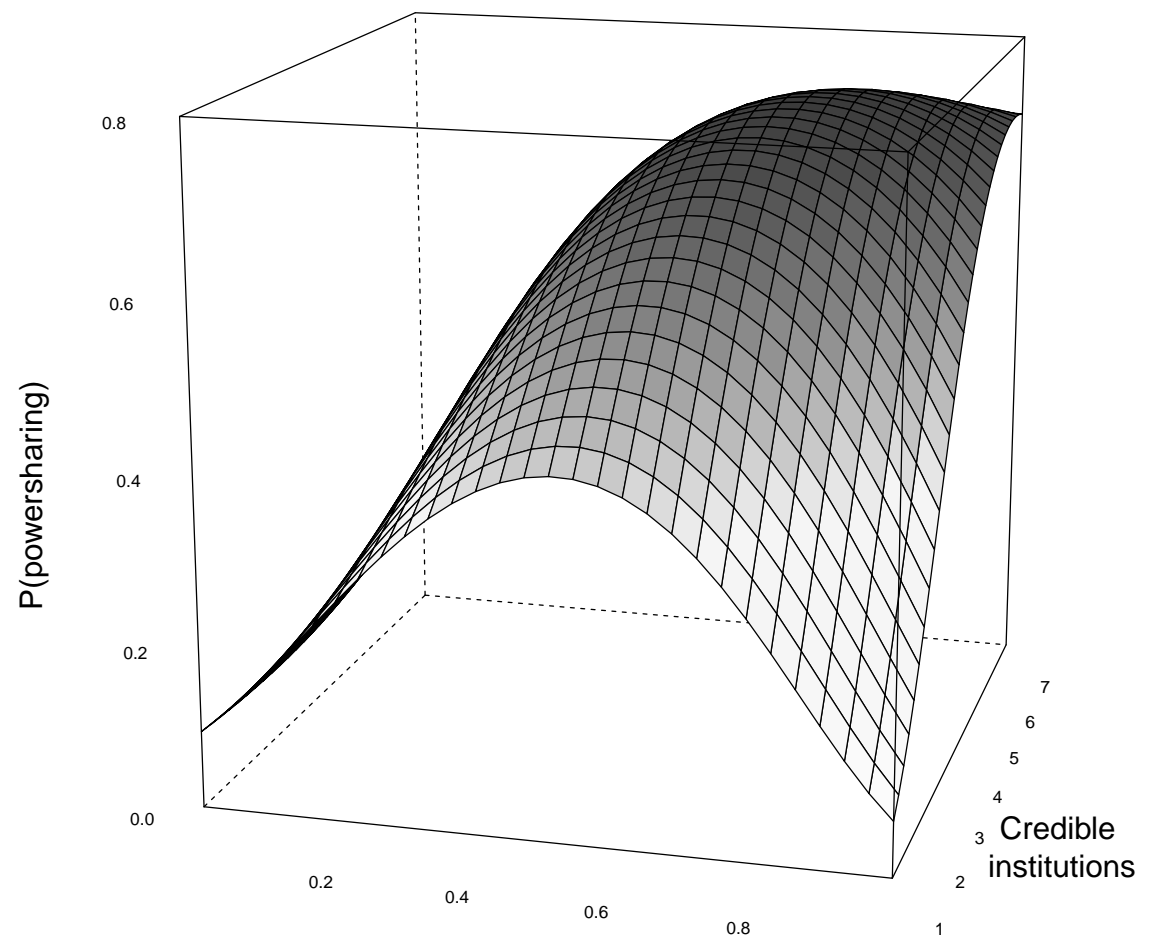

Relative group strength

Figure 4: Estimated Probability of Power Sharing

them. As groups get relatively stronger, power sharing becomes more likely, as suggested by the theoretical argument about co-optation. Under strong institutions, this monotonic relationship prevails, such that very large groups are almost certainly included in power sharing. However, under weak institutions where the government can hardly commit to the promise of power sharing, this relationship only holds up to a point. Here, overwhelmingly strong groups feature a declining probability of being part of power sharing arrangements, in line with arguments about risk-diversion. As a result, when there exists a strong commitment problem, the relationship between relative strength and power sharing follows an inverted U-shape.

The vertex of this curvilinear relationship is estimated where the group and government 
are roughly at parity, suggesting that power sharing can emerge endogenously even in weak states. In this case power sharing is self-enforcing through a mutual threat (cf. Roessler and Ohls, 2018). The figure shows how improving the quality of institutions (i.e. moving towards the back of the cube) can make power sharing possible even in constellations where one side is vastly superior.

In sum, the analysis so far suggests strongly that governments use power sharing in ways that follow a strategic logic. This overall picture is consistent with the estimated correlation between the players' stochastic components of their utilities: while the correlation coefficient $\rho_{1}$ is negative, $\rho_{2}$ is positive, suggesting that powerful groups are generally more likely to be offered power sharing (cf. Wucherpfennig, Hunziker and Cederman, 2016).

\section{Effect of power sharing on conflict}

Whether power sharing can secure peace in multiethnic states is contested, and concerns about endogeneity are at the core of this debate. By modeling the underlying structure of interaction, i.e. for the conditions under which power sharing is likely to emerge, it becomes possible to retrieve an improved estimate of the effect of power sharing on conflict. Based on the statistical model, this corresponds to the counterfactual of how a given group would have behaved had the government chosen differently. Thus, I compare predicted probabilities of fighting given either exclusion or powersharing, i.e.

$$
P(F \mid P S)-P(F \mid E)=: \frac{\widehat{P\left(Y_{4}\right)}}{\widehat{P\left(Y_{3}\right)}+\widehat{P\left(Y_{4}\right)}}-\frac{\widehat{P\left(Y_{2}\right)}}{\widehat{P\left(Y_{1}\right)}+\widehat{P\left(Y_{2}\right)}}
$$

across groups in the sample (see eq. 5).

Figure 5 depicts this estimate as the black dots (along with bootstrapped 95 percent confidence intervals) for selected scenarios. The gray diamonds denote the corresponding estimated effects derived from a standard probit that was estimated using all covariates (in-

cluding interaction terms; results not shown) that are also included in the strategic selection 


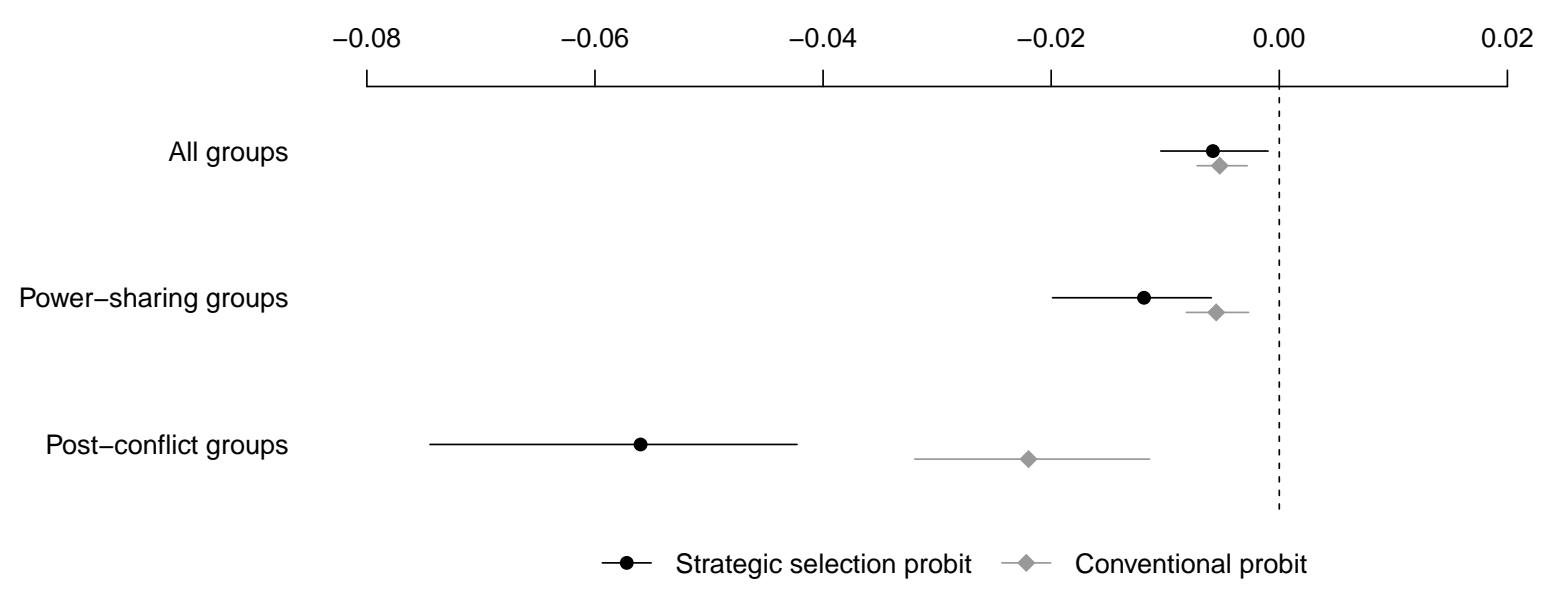

Figure 5: Change in Probability of Conflict under Power Sharing

estimator. All estimates were derived as average predicted probabilities, meaning that they reflect quantities of interest for real-world observations (i.e. combinations of values on the covariates) which are actually in the (sub-)sample (Hanmer and Ozan Kalkan, 2013).

The first two estimates correspond to the global, average effect of power sharing on civil conflict derived across all groups (dyads) in the sample. As can be seen, the strategic selection estimator yields a negative effect that is also statistically significant. Moreover, a comparison with the "naïve" probit estimate suggests that failure to account for strategic selection (i.e. endogeneity) leads to underestimating this pacifying effect by almost 20 percent.

The next two sets of estimates examine two concrete questions. First, has power sharing kept peace in those instances where it has been applied? To address this question, I generate average predicted probabilities for all power-sharing dyads in the sample. This analysis suggests that on average, power sharing has kept peace, and that conventional estimates tend to underestimate this effect. Second, I ask whether power sharing is generally suitable in post-conflict situations by generating average predicted probabilities for dyad-years in which the group previously fought. Again the answer is a clear 'yes', as implied by a sizable negative estimate. Moreover, in both scenarios, the pronounced difference compared to the "naïve" estimate further underlines the risk of underestimating the effectiveness of power 
sharing and suggests that it has been or could be particularly effective.

I conduct a number of robustness analyses to ensure that that these results are not idiosyncratic. These are presented in an Online Appendix. First, I examine whether the results also hold for a more restrictive dependent variable that captures governmental conflicts only (rather than territorial ones). Although the standard errors are slightly larger, the key findings are similar. Second, I employ an alternative operationalization of the commitment problem, using the 'political constraints index' from Henisz (2000), which attempts to identify underlying political structures and measure their ability to support credible policy commitments. Again, the key results are qualitatively unchanged. Finally, I explore whether the results are driven by the specific cases studied by Wucherpfennig, Hunziker and Cederman (2016), that is former British and French colonies. However, such concerns are not warranted. Re-estimating the model without these cases again does not affect the results.

\section{Discussion and Conclusion}

Whether power sharing is a suitable means to secure peace in multiethnic states has been the subject of intense scholarly debate. In this paper, I have highlighted how insufficient attention to reverse causation due to strategic interaction can hamper sound inference. Indeed, the challenge of endogenous institutions is well familiar to political scientists. My analysis has demonstrated that in observational research, the effects of institutional arrangements generally cannot be understood independently of their origins. Focusing on power sharing as an example, examining the specific conditions under which domestic challengers will be met with co-option (power sharing) or risk-diversion (exclusion) from governments has yielded a more complete picture, compared to existing work which so far has treated the two in isolation. Building on these insights, this article has directly addressed endogeneity concerns about the effect of power sharing on conflict, finding a peace-inducing effect. In other words, the evidence presented here suggests that critics of power sharing are likely to 
have overstated their case, at least in part because of insufficient attention to endogeneity.

In general, the result that power sharing is robustly associated with peace is encouraging from a policy-making perspective, precisely because power sharing is a political decision that can be manipulated also in the short-run - unlike other risk factors, such as underdevelopment, state capacity or the country's topography (cf. Fearon and Laitin, 2003). In other words, interethnic conflict can and should be resolved through political compromise. However, my findings indicate that this should not be taken for granted, and that this may hinge on an environment in which the promise of shared government is credible. More specifically, strengthening institutions will be particularly effective in cases of minority rule to prevent challengers from resorting to violence.

The Syrian case in the midst of a Arab Spring is a good example. Observing that other regimes in the region were faced by demands for greater inclusiveness, and that these demands were often pursued by violent means, a preemptive strategy for the regime of Bashar al-Assad could have been to accommodate previously excluded groups, especially the Sunnis. However, my analysis suggests that fears of future reprisals due to a vastly unfavorable balance of power between the ruling Alawite minority (13 percent of the country's population) and the Sunnis (65 percent) made this impossible, especially because of a looming commitment problem. Alawites reasonably had to fear that if Sunnis were granted access to state power, Alawites would be removed from power altogether, stripped off their privileges soon after, and were to face persecution, discrimination and repression.

Fueled by this mistrust, attempting to gain full control over the Syrian state through military victory thus became the opposition's objective. Indeed, according to the model analyzed in this paper, by providing weapons to the Syrian Free Army external states only made things worse, precisely because the Assad regime and the loyal Alawite minority anticipated future reprisals if previously excluded groups were to become empowered. Importantly, this dilemma arose not just because of the demographic imbalance, but because of a lack of an enforcement mechanism that would have made power sharing credible to the Sunni 
majority. ${ }^{21}$

To end civil wars, and to keep post-conflict peace, (UN) peacekeeping has become the standard policy prescription by the international community. Theoretically, this is justified because peacekeepers can, among others, help overcome commitment problems, thereby enabling lasting peace agreements (Walter, 2002). But peacekeeping does not need to be restricted to (post-) conflict situations; in principle it can also work preemptively (cf. Beardsley, Cunningham and White, 2017). So far, the United Nations Preventive Deployment Force (UNPREDEP) in the Republic of Macedonia has been the only 'proactive' mission in a country deemed to have a high risk of conflict outbreak. The results of my analysis suggest that such missions - by providing credible institutions that make power sharing possiblecould prove particularly helpful in countries seeking to peacefully transition out of minority rule. ${ }^{22}$ Arguably, external "help" of this kind could have made a difference in Syria, too. ${ }^{23}$

While I believe to have shed new light on an established question by disentangling some important aspects about the (two-way) relationship between power sharing and civil war in multiethnic states, my approach is not without limitations. These should be addressed by further research. For one, my approach features only one challenger, when in reality many governments are faced by multiple groups. While I have attempted to account for possible interdependence between groups through covariates, future extensions to the model (and estimator) should scrutinize such scenarios. Similarly, in order to minimize the number of decision variables, my approach assumes that credible institutional constraints are exogenous, contrary to argument that some authoritarians deliberately introduce constraining institutions (Wright, 2008; Boix and Svolik, 2013). In addition, my approach does not account for the possibility of non-violent coups as an additional mode by which governments

\footnotetext{
${ }^{21}$ Syria scores a 3 ("slight to moderate limitation") for executive constraints in 2010.

${ }^{22}$ Conceptually, this means that peacekeepers help moving from the front right corner to the back right corner in Figure 4.

${ }^{23}$ Syria briefly saw a small and limited UN peacekeeping mission (UNSMIS) in 2012.
} 
may lose power 24 Although many instances of infighting originate from coups - especially since the threshold for conflict onset is low at 25 battledeaths in my data-non-violent coups are currently subsumed in the 'peaceful power sharing' outcome. While reasonable as a first cut, future work should explore this in more detail. Moreover, future research should investigate the role of (endogenous) repression in maintaining enduring exclusion, since repressive regimes can increase the cost of rebellion, but maintaining the necessary apparatus implies enduring costs for the regime, too.

For now my evidence directly speaks in favor of a policy alternative that contradicts current claims that in order to curb ethnic civil war, one has to strengthen existing strongmen, to "un-mix" ethnic groups entirely through partition (Chapman and Roeder, 2007, Kaufmann, 1996), or even "give war a chance" (Luttwak, 1999). Rather, my main results uphold the intuitive and normatively desirable principle according to which compromise in the form of power sharing systematically reduces, rather spurs, inter-ethnic conflict.

\section{References}

Acemoglu, Daron and James A. Robinson. 2006. Economic Origins of Democracy and Dictatorship. Cambridge: Cambridge University Press.

Achen, Christoper H. 1986. The Statistical Analysis of Quasi-Experiments. Berkeley: University of California Press.

${ }^{24}$ Roessler (2011) considers coups, but his approach sees civil war (exclusively driven by exclusion) and coups (exclusively driven by power sharing) as the only threats governments have to face, and these are mutually exclusive. Thus, his approach conceptually omits many prominent infighting civil war cases, such as Lebanon, Rwanda, Yugoslavia or Zimbabwe. Moreover, his data do not distinguish inter- and intra-ethnic coups. 
Barry, Brian. 1975. "The Consociational Model and its Dangers." European Journal of Political Research 3(4):393-412.

Beardsley, Kyle, David E Cunningham and Peter B White. 2017. "Resolving civil wars before they start: The UN Security Council and conflict prevention in self-determination disputes." British Journal of Political Science 47(3):675-697.

Beiser-McGrath, Janina and Nils W Metternich. 2021. "Ethnic coalitions and the logic of political survival in authoritarian regimes." Comparative Political Studies 54(1):144-178.

van den Berghe, Pierre L. 1981. The Ethnic Phenomenon. New York: Elsevier.

Bhavnani, Ravi and Dan Miodownik. 2009. "Ethnic Polarization, Ethnic Salience, and Civil War." Journal of Conflict Resolution 53(1):30-49.

Binningsbø, Helga Malmin. 2013. "Power Sharing, Peace and Democracy: Any Obvious Relationships?" International Area Studies Review 16(1):89-112.

Binningsbø, Helga Malmin and Kendra Dupuy. 2009. "Using power-sharing to win a war: The implementation of the Lomé Agreement in Sierra Leone." Africa Spectrum 44(3):87107.

Boix, Carles. 2003. Democracy and Redistribution. Cambridge University Press.

Boix, Carles and Milan W. Svolik. 2013. "The Foundations of Limited Authoritarian Government: Institutions, Commitment, and Power-Sharing in Dictatorships." The Journal of Politics 75(2):300-316.

Bormann, Nils-Christian. 2019. "Uncertainty, cleavages, and ethnic coalitions." The Journal of Politics 81(2):471-486.

Bormann, Nils-Christian, Lars-Erik Cederman, Scott Gates, Benjamin AT Graham, Simon Hug, Kaare W Strøm and Julian Wucherpfennig. 2019. "Power sharing: Institutions, behavior, and peace." American Journal of Political Science 63(1):84-100. 
Buhaug, Halvard, Lars-Erik Cederman and Jan Ketil Rød. 2008. "Disaggregating EthnoNationalist Civil Wars: A Dyadic Test of Exclusion Theory." International Organization 62(3):531-551.

Cammett, Melani and Edmund Malesky. 2012. "Power sharing in postconflict societies: implications for peace and governance." Journal of Conflict Resolution 56(6):982-1016.

Carter, David B. 2010. "The strategy of territorial conflict." American Journal of Political Science 54(4):969-987.

Carter, David B. and Curtis S. Signorino. 2010. "Back to the Future: Modelling Time Dependence in Binary Data." Political Analysis 18(3):271-292.

Cederman, Lars-Erik, Andreas Wimmer and Brian Min. 2010. "Why Do Ethnic Groups Rebel? New Data and Analysis." World Politics 62(1):87-119.

Cederman, Lars-Erik, Kristian Skrede Gleditsch and Halvard Buhaug. 2013. Inequality, Grievances, and Civil War. Cambridge:: Cambridge University Press.

Cederman, Lars-Erik, Simon Hug, Andreas Schädel and Julian Wucherpfennig. 2015. "Territorial autonomy in the shadow of conflict: Too little, too late?" American Political Science Review 109(2):354-370.

Chapman, Thomas and Philip G. Roeder. 2007. "Partition as a Solution to Wars of Nationalism: The Importance of Institutions." American Political Science Review 101(4):2007.

Downes, Alexander B. 2004. "The Problem with Negotiated Settlements to Ethnic Civil Wars." Security Studies 13(4):230-279.

Dyrstad, Karin, Kristin M Bakke and Helga M Binningsbø. forthcoming. "Perceptions of Peace Agreements and Political Trust in Post-War Guatemala, Nepal, and Northern Ireland." International Peacekeeping . 
Fearon, James D. 1995. "Rationalist Explanations for War." International Organization 49(3):379-414.

Fearon, James D. 2010. "Governance and Civil War Onset." World Development Report 2011 Background Paper .

Fearon, James D. and David D. Laitin. 2003. "Ethnicity, Insurgency, and Civil War." American Political Science Review 97(1):75-89.

Fearon, James D., Kimuli Kasara and David D. Laitin. 2007. "Ethnic Minority Rule and Civil War Onset." American Political Science Review 101(1):187-193.

Francois, Patrick, Ilia Rainer and Francesco Trebbi. 2015. "How is power shared in Africa?" Econometrica 83(2):465-503.

Gandhi, Jennifer. 2008. Political Institutions under Dictatorship. Cambridge: Cambridge University Press.

Gandhi, Jennifer and Adam Przeworski. 2006. "Cooperation, cooptation, and rebellion under dictatorships." Economics \& Politics 18(1):1-26.

Gates, Scott, Benjamin A.T. Graham, Yonatan Lupu, Håvard Strand and Kaare W. Strøm. 2016. "Power Sharing, Protection, and Peace." The Journal of Politics 78(2):512-526.

Gleditsch, Kristian Skrede. 2002. "Expanded trade and GDP data." Journal of Conflict Resolution 46(5):712-724.

Gleditsch, Kristian Skrede and Andrea Ruggeri. 2010. "Political Opportunity Structures, Democracy, and Civil War." Journal of Peace Research 47(3):299-310.

Gleditsch, Nils Petter, Peter Wallensteen, Mikael Eriksson, Margareta Sollenberg and Håvard Strand. 2002. "Armed Conflict 1946-2001: A New Dataset." Journal of Peace Research 39(5):616-637. 
Gurr, Ted Robert. 1993. "Why Minorities Rebel: A Global Analysis of Communal Mobilization and Conflict since 1945." International Political Science Review 14(2):161-201.

Gurr, Ted Robert. 2000a. "Ethnic Warfare on the Wane." Foreign Affairs 79(3):52-64.

Gurr, Ted Robert. 2000b. Peoples versus States: Minorities at Risk in the New Century. United States Institute of Peace Press.

Hanmer, Michael J and Kerem Ozan Kalkan. 2013. "Behind the curve: Clarifying the best approach to calculating predicted probabilities and marginal effects from limited dependent variable models." American Journal of Political Science 57(1):263-277.

Hartzell, Caroline A. 1999. "Explaining the stability of negotiated settlements to intrastate wars." Journal of conflict resolution 43(1):3-22.

Hartzell, Caroline A. 2009. "Settling civil wars: Armed opponentsâ $€^{\top M}$ fates and the duration of the peace." Conflict Management and Peace Science 26(4):347-365.

Hartzell, Caroline A. and Matthew Hoddie. 2007. Crafting Peace: Power-Sharing Institutions and the Negotiated Settlement of Civil Wars. University Park: Pennsylvania State University Press.

Hartzell, Caroline, Matthew Hoddie and Donald S. Rothchild. 2001. "Stabilizing the Peace after Civil War: An Investigation of Some Key Variables." International Organization $55(1): 183-208$.

Helmke, Gretchen and Steven Levitsky. 2004. "Informal Institutions and Comparative Politics: A Research Agenda." Perspectives on Politics 2(4):725-740.

Henisz, Witold J. 2000. "The institutional environment for economic growth." Economics 6 Politics 12(1):1-31.

Horowitz, Donald L. 1985. Ethnic Groups in Conflict. Berkeley: University of California Press. 
Jarstad, Anna K and Desirée Nilsson. 2008. "From Words to Deeds: The Implementation of Power-Sharing Pacts in Peace Accords." Conflict Management and Peace Science $25(3): 206-223$.

Kaufmann, Chaim. 1996. "Possible and Impossible Solutions to Ethnic Civil Wars." International Security 20(4):136-175.

Kreutz, Joakim. 2010. "How Armed Conflicts End." Journal of Peace Research 47(2):243250.

Leemann, Lucas. 2014. "Strategy and Sample Selection: A Strategic Selection Estimator." Political Analysis 22(3):374-397.

Lijphart, Arend. 1969. "Consociational Democracy." World Politics 21(2):207-225.

Lijphart, Arend. 1977. Democracy in Plural Societies: A Comparative Exploration. New Haven: Yale University Press.

Luttwak, Edward N. 1999. "Give War a Chance." Foreign Affairs 78(4):36-44.

Magaloni, Beatriz. 2008. "Credible Power-Sharing and the Longevity of Authoritarian Rule." Comparative Political Studies 41(4-5):715-741.

Marshall, Monty G., Ted Robert Gurr and Keith Jaggers. 2017. Polity IV Project: Dataset Users' Manual. Center for Systemic Peace: www.systemicpeace.org/polity/polity4.htm.

Mattes, Michaela and Burcu Savun. 2009. "Fostering Peace After Civil War: Commitment Problems and Agreement Design." International Studies Quarterly 53(3):737-759.

McKelvey, Richard D. and Thomas R. Palfrey. 1998. "Quantal response equilibria for extensive form games." Experimental Economics 1(1):9-41.

Nilsson, Desirée. 2008. "Partial peace: Rebel groups inside and outside of civil war settlements." Journal of Peace Research 45(4):479-495. 
Norris, Pippa. 2008. Driving Democracy: Do Power-Sharing Institutions Work? Cambridge University Press.

Petersen, Roger D. 2002. Understanding Ethnic Violence: Fear Hatred, and Resentment in Twentieth-Century Eastern Europe. Cambridge: Cambridge University Press.

Przeworski, Adam and Jennifer Gandhi. 2006. "Cooperation, Cooptation, and Rebellion under Dictatorship." Economics and Politics 18(1):1-26.

Rabushka, Alvin and Kenneth A. Shepsle. 1972. Politics in Plural Societies. Stanford University Press.

Reynal-Querol, Marta. 2002. "Ethnicity, Political Systems, and Civil Wars." Journal of Conflict Resolution 46(1):29.

Rodrik, Dani. 2012. "Why We Learn Nothing from Regressing Economic Growth on Policies." Seoul Journal of Economics 25:137-151.

Roeder, Philip G. 2005. Power Dividing as an Alternative to Power Sharing. In Sustainable Peace: Power Sharing and Democracy after Civil Wars, ed. Philip G. Roeder and Donald S. Rothchild. Cornell University Press pp. 51-82.

Roessler, Philip. 2011. "The Enemy Within: Personal Rule, Coups and Civil War." World Politics 63(2):300-346.

Roessler, Philip and David Ohls. 2018. "Self-Enforcing Power Sharing in Weak States." International Organization 72(2):423-454.

Rothchild, Donald S. and Philip G. Roeder. 2005. Power Sharing as an Impediment to Peace and Democracy. In Sustainable Peace: Power Sharing and Democracy after Civil Wars, ed. Philip G. Roeder and Donald S. Rothchild. Cornell University Press pp. 29-50. 
Saideman, Stephen M., David J. Lanoue, Michael Campenni and Samuel Stanton. 2002. "Democratization, Political Institutions, and Ethnic Conflict." Comparative Political Studies $35(1): 103-129$.

Schneckener, Ulrich. 2002. "Making Power-Sharing Work: Lessons from Successes and Failures in Ethnic Conflict regulation." Journal of Peace Research 39(2):203-228.

Schneider, Gerald and Nina Wiesehomeier. 2008. "Rules That Matter: Political Institutions and the Diversity-Conflict Nexus." Journal of Peace Research 45(2):183-203.

Selway, Joel and Kharis Templeman. 2012. "The Myth of Consociationalism? Conflict Reduction in Divided Societies." Comparative Political Studies 45(12):1542-1571.

Signorino, Curtis. 2002. "Strategy and selection in international relations." International Interactions 28(1):93-115.

Signorino, Curtis S. 1999. "Strategic interaction and the statistical analysis of international conflict." The American Political Science Review 93(2):279-297.

Signorino, Curtis S. 2003. "Structure and Uncertainty in Discrete Choice Models." Political Analysis 11(4):316-344.

Signorino, Curtis S. and Kuzey Yilmaz. 2003. "Strategic Misspecification in Regression Models." American Journal of Political Science 47(3):551-566.

Simon, Herbert A. 1955. "A Behavioral Model of Rational Choice." The Quarterly Journal of Economics 69(1):99.

Sovey, Allison J. and Donald P. Green. 2011. "Instrumental Variables Estimation in Political Science: A Readers' Guide." American Journal of Political Science 55(1):188-200.

Spears, Ian S. 2000. "Understanding inclusive peace agreements in Africa: the problems of sharing power." Third World Quarterly 21(1):105-118. 
Spears, Ian S. 2013. "Africa's informal power-sharing and the prospects for peace." Civil Wars 15(1):37-53.

Strøm, Kaare W, Scott Gates, Benjamin AT Graham and Håvard Strand. 2017. "Inclusion, Dispersion, and Constraint: Powersharing in the World's States, 1975-2010." British Journal of Political Science 47(1):165-185.

Svolik, Milan W. 2012. The Politics of Authoritarian Rule. Cambridge University Press.

Toft, Monica Duffy. 2010. "Ending Civil Wars: A Case for Rebel Victory?" International Security 34(4):7-36.

Tull, Denis M and Andreas Mehler. 2005. "The hidden costs of power-sharing: Reproducing insurgent violence in Africa." African affairs 104(416):375-398.

Vogt, Manuel, Nils-Christian Bormann, Seraina Rüegger, Lars-Erik Cederman, Philipp Hunziker and Luc Girardin. 2015. "Integrating Data on Ethnicity, Geography, and Conflict: The Ethnic Power Relations Data Set Family." Journal of Conflict Resolution 59(7):13271342.

Walter, Barbara F. 1997. "The Critical Barrier to Civil War Settlement." International Organization 51(3):335-364.

Walter, Barbara F. 2002. Commiting to Peace: The Successful Settlement of Civil Wars. Princeton: Princeton University Press.

Walter, Barbara F. 2009. Reputation and Civil War: Why Some Separatist Conflicts Are So Violent. Cambridge: Cambridge University Press.

Wilde, Joachim. 2000. "Identification of Multiple Equation Probit Models With Endogenous Dummy Regressors." Economics Letters 69(3):309-312.

Wright, Joseph. 2008. "Do authoritarian institutions constrain? How legislatures affect economic growth and investment." American Journal of Political Science 52(2):322-343. 
Wucherpfennig, Julian, Nils W. Metternich, Lars-Erik Cederman and Kristian Skrede Gleditsch. 2012. "Ethnicity, the State, and the Duration of Civil Wars." World Politics 64(1):79-115.

Wucherpfennig, Julian, Philipp Hunziker and Lars-Erik Cederman. 2016. "Who Inherits the State? Colonial Rule and Postcolonial Conflict." American Journal of Political Science 60(4):882-898. 